University of New Hampshire

University of New Hampshire Scholars' Repository

$12-2009$

\title{
Regional variation in perceptions about climate change.
}

Lawrence C. Hamilton

University of New Hampshire, lawrence.hamilton@unh.edu

Barry D. Keim

Louisiana State University

Follow this and additional works at: https://scholars.unh.edu/soc_facpub

Part of the Sociology Commons

\section{Comments}

This is the pre-peer reviewed version of the following article: Hamilton, L. C. and Keim, B. D. (2009), Regional variation in perceptions about climate change. Int. J. Climatol., 29: 2348-2352, which has been published in final form at https://dx.doi.org/10.1002/joc.1930. This article may be used for non-commercial purposes in accordance with Wiley Terms and Conditions for Self-Archiving.

\section{Recommended Citation}

Hamilton, L. C. and Keim, B. D. (2009), Regional variation in perceptions about climate change. Int. J. Climatol., 29: 2348-2352. doi: 10.1002/joc.1930

This Article is brought to you for free and open access by the Sociology at University of New Hampshire Scholars' Repository. It has been accepted for inclusion in Sociology Scholarship by an authorized administrator of University of New Hampshire Scholars' Repository. For more information, please contact Scholarly.Communication@unh.edu. 
AUTHORS' DRAFT. Final version published in:

International Journal of Climatology (2009) 29(15):2348-2352. doi: 10.1002/joc.1930

\title{
REGIONAL VARIATION IN PERCEPTIONS ABOUT CLIMATE CHANGE
}

\author{
Lawrence C. Hamilton \\ Department of Sociology \\ University of New Hampshire \\ Durham, NH 03824 \\ Barry D. Keim \\ Department of Geography and Anthropology \\ Louisiana State University \\ Baton Rouge, LA 70803
}

\section{ACKNOWLEDGMENTS}

This research has been supported by grants to the Carsey Institute from the W.K. Kellogg, Ford, and Mary Reynolds Babcock Foundations and the Neil and Louise Tillotson Fund of the New Hampshire Charitable Foundation.

\begin{abstract}
A 2007 survey covering rural areas in nine U.S. states provides data on perceived local impacts of climate change. Perceptions vary from region to region, with a pattern suggesting links to real climate - specifically, to winter warming in snow country. Multivariate analysis using mixed-effects ordered logit regression confirms a significant perception-temperature relationship, net of individual background and ideological characteristics, and of regional variations. These findings invite more detailed research.
\end{abstract}

\section{INTRODUCTION}

Recent physical data show that climate change is in progress, but with noteworthy regional and interannual variations (IPCC 2007a-d). A 2007 survey covering rural areas in nine U.S. states provides data on regional variations in perceptions about climate change. Perceptions appear different from region to region, with a pattern suggesting links to real climate.

The Community and Environment in Rural America (CERA) survey, carried out by Carsey Institute researchers in 2007, aimed to learn how people in different rural areas viewed changes in their communities, local environments and in their own lives. The first stage involved telephone interviews with 7,842 people living in 19 rural counties of nine states (Figure 1). Following an examination of data on all U.S. counties, these 19 were chosen to represent geographically and socioeconomically diverse types of rural places. They represent a broad range of physical climates within the conterminous U.S. as well.

Random-sample telephone interviews with about 100 questions covered topics ranging from respondents' personal background and experiences (such as family, jobs, education and life situation) to their migration history and views about their local government and community. We calculated probability weights to offset design bias arising from household size, and make minor adjustments toward Census age/sex/race distributions within each region. Site selection, sampling methods, question wording and basic results are described in a report by Hamilton et al. (2008; also see Hamilton 2007a-b). 


\section{REGIONAL VARIATION}

CERA results showed strong regional contrasts. For example, $47 \%$ of the respondents from Colorado mountain counties, but only $7 \%$ from Kansas farm counties, agreed that urban sprawl or rapid development had major effects on their family or community over the past five years. Regional perceptions about sprawl correlate with objectively-measured population growth.

The sprawl question was among a set of five items that included one on climate change: I'm going to read a list of environmental issues that might be problems in some rural places. With regard to the place where YOU live, for each issue I'd like to know whether you think this has had no effect, had minor effects, or had major effects ON YOUR FAMILY OR COMMUNITY OVER THE PAST 5 YEARS?

Conversion of farmland to other uses

Loss of forestry jobs or income

Water quality or supply problems

Global warming or climate change

Urban sprawl or rapid development of the countryside

Question wording was deliberately broad, to encompass variations in local conditions. Figure 2 shows responses to the climate question by region. Major or minor effects were reported by $70 \%$ of northern New Hampshire respondents, and $63 \%$ of those in western Maine, but only $48 \%$ from Kansas.

Looking at these results, we noticed that the three regions showing the highest levels of concern represent snow-country areas (in northern New Hampshire, western Maine and central Colorado) that recently experienced trends towards warmer and less-snowy winters, with newsworthy impacts on winter recreation, forest health and daily life (Hamilton et al. 2003, 2007; NERA 2001; USGCRP 2003). Might the pattern of climate responses in Figure 2 partly reflect a winter-warming effect, as the pattern of sprawl responses reflect population growth?

To explore this idea, we constructed rough indicators based on temperature records from the United States Historical Climate Network (USHCN; Karl et al. 1990, 1996). Temperature data include adjustments to correct for biases induced by invalid outliers, changes in time of observation, changes in instrumentation, random relocations of stations and urban warming. As a result, these data provide the best opportunity to capture local and regional temperature trends (e.g., Allard and Keim 2007; Trobulak and Wolfson 2004; Keim et al. 2003). We used an updated (2007) version of this dataset, made available recently through the National Climatic Data Center. Stations near the county clusters were selected to estimate regional temperature trends (Figure 1).

Monthly, seasonal and annual temperatures were derived from average monthly minimum and maximum temperature data. Winter temperatures were used because of our observation about Figure 2, and also because they exhibit greater interannual variability, which could result in more noticeable impacts (e.g., the duration and depth of snow cover, or persistence of ice over lakes) than milder variations in warm-season temperatures. A thirty-eight year window (1970-2007) should capture modern climate change as indicated by the upswing in global temperatures.

To estimate trends we fit a mixed-effects model of the form

$$
\text { temp }_{i j}=\beta_{0}+\beta_{1} \text { year }_{i j}+\zeta_{0 j}+\zeta_{1 j} \text { year }_{i j}+\varepsilon_{i j}
$$

where temp $_{i j}$ is average winter (DJF) temperature for year $i$ in rural region $j$. Year simply denotes calendar year $(1970,1971, \ldots 2007)$. The $\beta$ parameters represent fixed effects - intercept $\left(\beta_{0}\right)$ and slope $\left(\beta_{1}\right)$ of temperature trends for all places considered together. $\zeta_{j}$ parameters represent random intercepts $\left(\zeta_{0 j}\right)$ and slopes $\left(\zeta_{1 j}\right)$ unique to each region. $\varepsilon_{i j}$ are random disturbances, representing everything else (besides linear trends) causing year-to-year variation in temperatures. Rabe-Hesketh and Skrondal (2008) provide a detailed account of mixed-effects modeling (also see StataCorp 2007; Hamilton 2009). Trends for the $j$ th region were estimated by adding the fixed slope $\left(\beta_{1}\right)$ to the best linear unbiased prediction of that region's random slope $\left(\zeta_{1 j}\right)$.

Figure 3 integrates survey and climate data by graphing responses to the climate question (Figure 2 ) against winter temperature slopes $\left(\beta_{1}+\zeta_{1 j}\right.$ from [1]). Consistent with our hypothesis, perceptions of 
climate-change effects tend to be higher in regions that experienced the most winter warming. New Hampshire was highest on both counts, with the greatest proportion of respondents perceiving climatechange effects, and also the steepest winter temperature increase. Maine and Colorado respondents were not far behind. We performed similar analyses using annual and other-season temperature trends, but found the most consistent effects for winter.

Two regions, in the Mississippi delta and Kansas farm country, depart noticeably from the pattern of perceived impacts rising with observed winter temperature trends. In post-Katrina Mississippi, some respondents no doubt had hurricanes or flooding in mind as an "effect of climate change." Furthermore, in the years just prior to the survey the United States Drought Monitor depicts frequent drought conditions in this agricultural region. The Mississippi anomaly highlights limitations of our onedimensional climate indicator, and scope for improvement in future research which should include weather and climate extremes.

The Kansas anomaly, on the other hand, likely reflects social rather than climatic complexity. People in the rural Kansas region surveyed are politically conservative, more so than any others in this study (Hamilton 2007b). U.S. public opinion surveys consistently find that political orientation shapes views about climate change.

\section{INDIVIDUAL AND REGIONAL EFFECTS}

Figure 3 encourages speculation that climate might influence perceptions. At the same time, scatter around the line emphasizes that other things influence perceptions as well. Previous studies have identified a number of ideological, socioeconomic and demographic factors related to opinions about climate change (e.g., Dietz et al. 2007; Dunlap 2008; Finucane et al. 2000; Kahan et al. 2005; Krosnick et al. 2006; Hamilton 2008; Wood and Vedlitz 2007), and also noted regional variation (e.g., Shwom et al. 2008).

Our next step involves testing whether temperature trends have a detectable effect net of individual characteristics, and also net of regional variations unrelated to temperature. Modeling by mixed-effects ordered logit regression (Rabe-Hesketh and Skrondal 2008; also see Hosmer and Lemeshow 2000; Long 1997) suits the ordinal climate variable, and allows for geographical variations or clustering that would bias estimation in a one-level model.

Table 1 displays results from the regression of climate on individual characteristics and regional temperature trends, with random intercepts. Individual-level predictors include eight demographic, socioeconomic or ideological indicators suggested by previous research. In addition to education and political party, we include the interaction term education $\times$ party.

Table 1 shows that, other things being equal, local climate-change effects are less often perceived by respondents who are male or high-income - findings consistent with studies of risk perception (Finucane et al. 2000; Kahan et al. 2005). Race, age and newcomer status have no significant effects.

Republican party identification and more frequent religious-service attendance reduce the probability of perceiving climate-change effects. Other researchers have noted that ideological predispositions can filter how people process information (e.g., Krosnik et al. 2006; Shwom et al. 2008; Wood and Vedlitz 2007). Individuals with conservative ideologies tend to discount anthropogenic climate change (Dietz et al. 2007; Dunlap 2008; Dunlap and McCright 2008; Pew 2006, 2007).

One recent poll found that the proportion believing that global warming is real increased with education among Democrats, and decreased with education among Republicans (Pew 2007). This interaction reflects efforts to reframe climate change from nonpartisan science question to political wedge issue, through arguments aimed at educated voters (Freudenburg 2000; Jaques et al. 2008; McCright and Dunlap 2000, 2003, 2008; UCS 2007). Multivariate analyses of other data have detected similar effects (Hamilton 2008, 2009). We therefore hypothesized that the education $\times$ party interaction effect should be negative; Table 1 confirms that it is. Among Democrats, increasing education is associated with higher probability of perceived effects. Among Republicans, the opposite is true. 
Winter warming increases the probability of perceiving local climate change - even after adjusting for individual demographic, socioeconomic or ideological predictors, and for unexplained regional differences. In fact, temperature trends appear second only to political party as the strongest single predictor. Table 1 thus supports the hypothesis that a real climate signal, distinguishable from social and regional effects, underlies these survey responses - despite the broad indicators used.

A likelihood-ratio test confirms that the model with random intercepts fits better $(p=.008)$ than a similar model with fixed effects only. In other words, there exists significant regional variation not explained by other variables in the model. More elaborate models including random slopes do not bring further improvement.

\section{DISCUSSION}

Our perceptions and climate-change indicators are very simple, but nevertheless exhibit statistically significant relationships with the expected sign, both in aggregate-level bivariate analysis and in individual-level multivariate analysis controlling for background characteristics and regional variation.

Figure 3 suggests that our findings partly reflect warming winters in snow country, which have had important and much-discussed impacts (e.g., Huntington et al. 2004). This intuitively appealing idea parallels earlier CERA findings of relationships between perceived impacts of urban sprawl and actual population growth, and between opinions favoring conservation over jobs and local unemployment. In each case, CERA questions referred to local impacts, which could boost their connection to objective local conditions.

The relatively strong impacts perceived by respondents in the Mississippi Delta, where floods, droughts or hurricanes are more salient than warming winters, underlines the desirability of using multiple indicators in future research. We suspect that specific, multidimensional climate indicators, matched with similarly specific survey questions, could uncover stronger perception-climate relationships than those observed using very general one-dimensional indicators in our study. Developing multidimensional climate indicators for integration with survey research would itself be a substantial project, needing more geographical diversity (or degrees of freedom) than the nine regions described here. 


\section{REFERENCES}

Allard, J., and B.D. Keim. 2007. "Spuriously induced temperature trends in the Southeast United States." Theoretical and Applied Climatology 88(1-2): 103-110. DOI 10.1007/s00704-006-0229-5.

Dietz, T., A. Dan and R. Shwom. 2007. "Support for climate change policy: Social psychological and social structural influences." Rural Sociology 72:185-214.

Dunlap, R.E. 2008. “Climate-change views: Republican-Democratic gaps expand.”

Gallup, http://www.gallup.com/poll/107569/ClimateChange-Views-RepublicanDemocratic-Gaps-Expand.aspx accessed 6/25/2008.

Dunlap, R.E. and A.M. McCright. 2008. "A widening gap: Republican and Democratic views on climate change." Environment 50(5):26-35.

Freudenburg, W.R. 2000. "Social constructions and social constrictions: Toward analyzing the social construction of 'the naturalized' as well as 'the natural." Pp. 103-119 in G. Spaargaren, A.P.J. Mol and F.H. Buttel (eds.), Environment and Global Modernity. London: Sage.

Finucane, M.L., P. Slovic, C,K. Mertz, J. Flynn and T.A. Satterfield. 2000. "Gender, race, and perceived risk: The 'white male' effect." Health, Risk and Society 2(2):159-172.

Hamilton, L.C., D.E. Rohall, B.C. Brown, G. Hayward and B.D. Keim. 2003. "Warming winters and New Hampshire's lost ski areas: An integrated case study." International Journal of Sociology and Social Policy 23(10):52-73.

Hamilton, L.C. 2007a. "A new survey of views from rural America." http://www.carseyinstitute.unh.edu/snapshot_viewsfromruralamerica.html Durham, NH: Carsey Institute.

Hamilton, L.C. 2007b. "Views from the Heartland." http://www.carseyinstitute.unh.edu/snapshot kansas.html Durham, NH: Carsey Institute.

Hamilton, L.C. 2008. "Who cares about polar regions? Results from a survey of U.S. public opinion." Arctic, Antarctic, and Alpine Research 40(4):671-678.

Hamilton, L.C. 2009. Statistics with Stata, version 10. Belmont, CA: Cengage.

Hamilton, L.C., B.C. Brown and B.D. Keim. 2007. "Ski areas, weather and climate: Time series models for New England case studies.” International Journal of Climatology 27:2113-2124.

Hamilton, L.C., L.R. Hamilton, C.M. Duncan and C.R. Colocousis. 2008. Place Matters: Challenges and Opportunities in Four Rural Americas. Durham, NH: Carsey Institute, University of New Hampshire.

Hosmer, D.W. and S. Lemeshow. 2000. Applied Logistic Regression. New York: Wiley.

Huntington, T.G., G.A. Hodgkins, B.D. Keim and R.W. Dudley. 2004. "Changes in the proportion of 
precipitation occurring as snow in New England (1949-2000).” Journal of Climate 17:2626-2636.

IPCC. 2007a. Climate Change 2007 - The Physical Science Basis.

Contribution of Working Group I to the Fourth Assessment Report of the Intergovernmental Panel on Climate Change. Cambridge: Cambridge University Press.

IPCC. 2007b. Climate Change 2007 - Impacts, Adaptation and Vulnerability. Contribution of Working Group II to the Fourth Assessment Report of the Intergovernmental Panel on Climate Change. Cambridge: Cambridge University Press.

IPCC. 2007c. Climate Change 2007 - Mitigation of Climate Change. Contribution of Working Group III to the Fourth Assessment Report of the Intergovernmental Panel on Climate Change. Cambridge: Cambridge University Press.

IPCC. 2007d. Climate Change 2007 - Synthesis Report. Cambridge: Cambridge University Press.

Jacques, P.J., R.E. Dunlap and M. Freeman. 2008. "The organisation of denial: Conservative think tanks and environmental scepticism." Environmental Politics 17(3):349-385.

Kahan, D.M., D. Braman, J. Gastil, P. Slovic and C.K. Mertz. 2005. "Gender, race, and risk perception: The influence of cultural status anxiety." Public Law and Legal Theory Research Paper No. 86. New Haven, CT: Yale Law School.

Karl, T.R., C.N. Williams, Jr, and F.T. Quinlan. 1990. United States Historical Climatology Network (HCN) Serial Temperature and Precipitation Data. ORNL/CDIAC-30, NDP-019/R1. Oak Ridge, TN: Carbon Dioxide Information Analysis Center, Oak Ridge National Laboratory.

Karl, T.R. R.W. Knight, D.R. Easterling, and R.G. Quayle. 1996. "Indices of climate change for the United States." Bulletin of the American Meteorological Society 77:279-292.

Keim, B.D., A. Wilson, C.P. Wake, and T. Huntington. 2003. "Are there spurious temperature trends in the United States Climate Division database?" Geophysical Research Letters

30(7):10.1029/2002GL016295.

Krosnick, J.A., A.L. Holbrook, L. Lowe, P.S. Visser. 2006. "The origins and consequences of democratic citizens' policy agendas: A study of popular concern about global warming." Climatic Change doi: 10.1007/s10584-006-9068-S.

Long, J.S. 1997. Regression Models for Categorical and Limited Dependent Variables. Thousand Oaks, CA: Sage.

McCright, A.M. and R.E. Dunlap. 2000. "Challenging global warming as a problem: An analysis of the conservative movement's counter-claims." Social Problems 47:499-522.

McCright, A.M. and R.E. Dunlap. 2003. "Defeating Kyoto: The conservative movement's impact on the U.S. climate change policy." Social Problems 50:348-373.

McCright, A.M. and R.E. Dunlap. 2008. "Anti-reflexivity: The American conservative movement's success in undermining climate change science and policy." Department of Sociology, Michigan State University. 
NERA (New England Regional Assessment Group). 2001. Preparing for a Changing Climate: The Potential Consequences of Climate Variability and Change. Durham, NH: University of New Hampshire.

Pew Research Center. 2006. "Little consensus on global warming: Partisanship drives opinion." http://people-press.org/reports/display.php3?ReportID=280 accessed 11/17/2007.

Pew Research Center. 2007. "Global warming: A divide on causes and solutions." http://people-press.org/reports/pdf/303.pdf accessed 12/14/2007.

Rabe-Hesketh, S. and A. Skrondal. 2008. Multilevel and Longitudinal Modeling Using Stata, 2nd edition. College Station, TX: Stata Press.

Shwom, R., A. Dan and T. Dietz. 2008. "The effects of information and state of residence on climate change policy preferences." Climatic Change 90:343-358.

Slimak, M.W. and T. Dietz. 2006. "Personal values, beliefs, and ecological risk perception." Risk Analysis 26(6):1689-1705.

StataCorp. 2007. Stata Longitudinal/Panel Data Analysis Manual, Release 10. College Station, TX: Stata Press.

Trombulak, S.C., and R. Wolfson. 2004. "Twentieth century climate change in New England and New York, USA.” Geophysical Research Letters 31(19): Art. No. L19202.

UCS. 2007. Smoke, Mirrors and Hot Air: How ExxonMobil Uses Big Tobacco's Tactics to Manufacture Uncertainty about Climate Science. Cambridge, MA: Union of Concerned Scientists.

USGCRP. 2003. "US National Assessment of the Potential Consequences of Climate Variability and Change: Rocky Mountain /Great Basin Region.” U.S. Global Change Research Program http://www.usgcrp.gov/usgcrp/nacc/education/rockies-greatbasin/rockiesandgreatbasin-edu-6.htm accessed 8/10/2008.

Wood, B.D. and A. Vedlitz. 2007. "Issue definition, information processing, and the politics of global warming." American Journal of Political Science 51(3):552-568. 


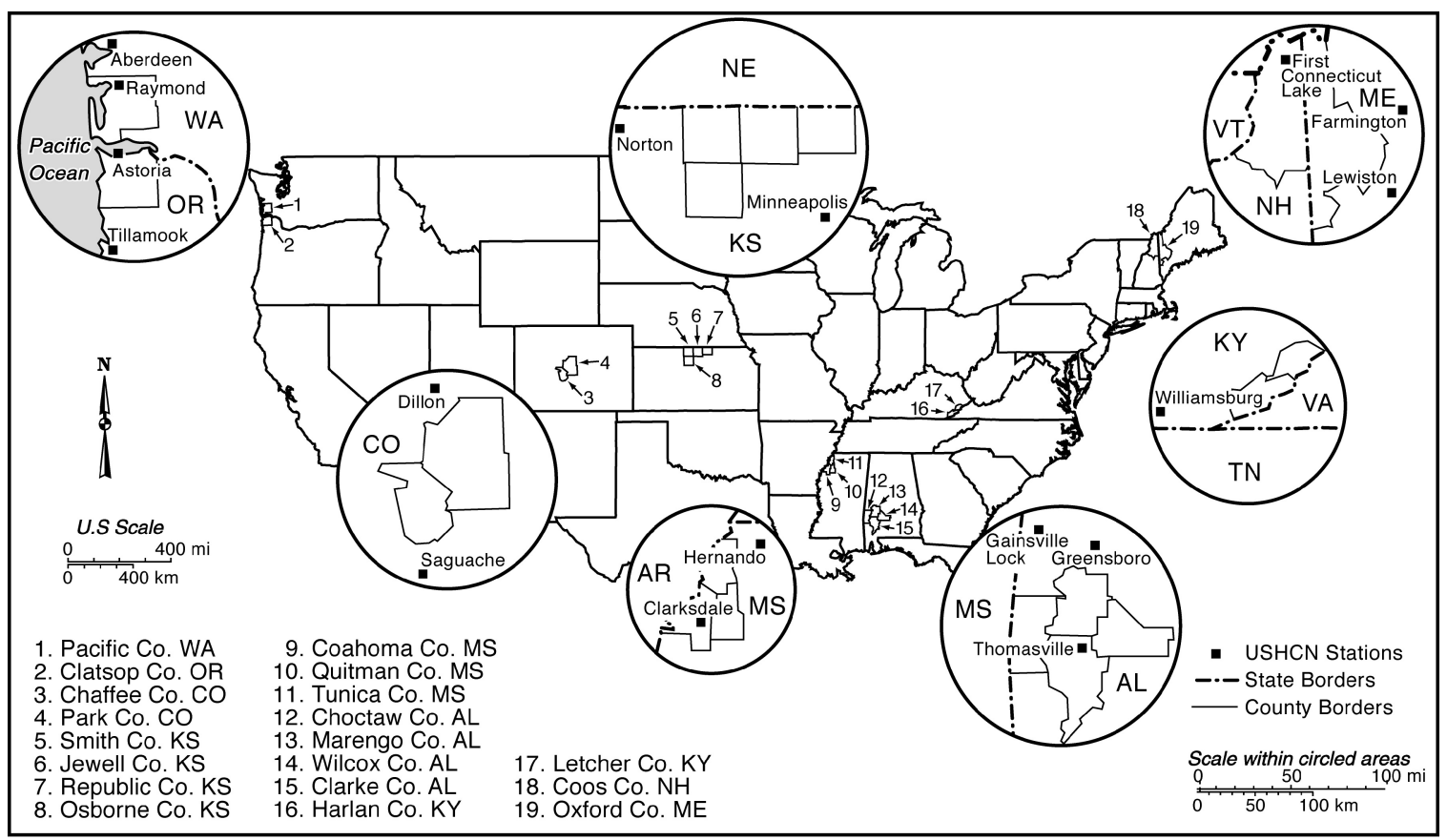

Figure 1: Counties sampled by the 2007 CERA telephone surveys, representing selected rural regions. Insets show climate stations used from the United States Historical Climate Network.

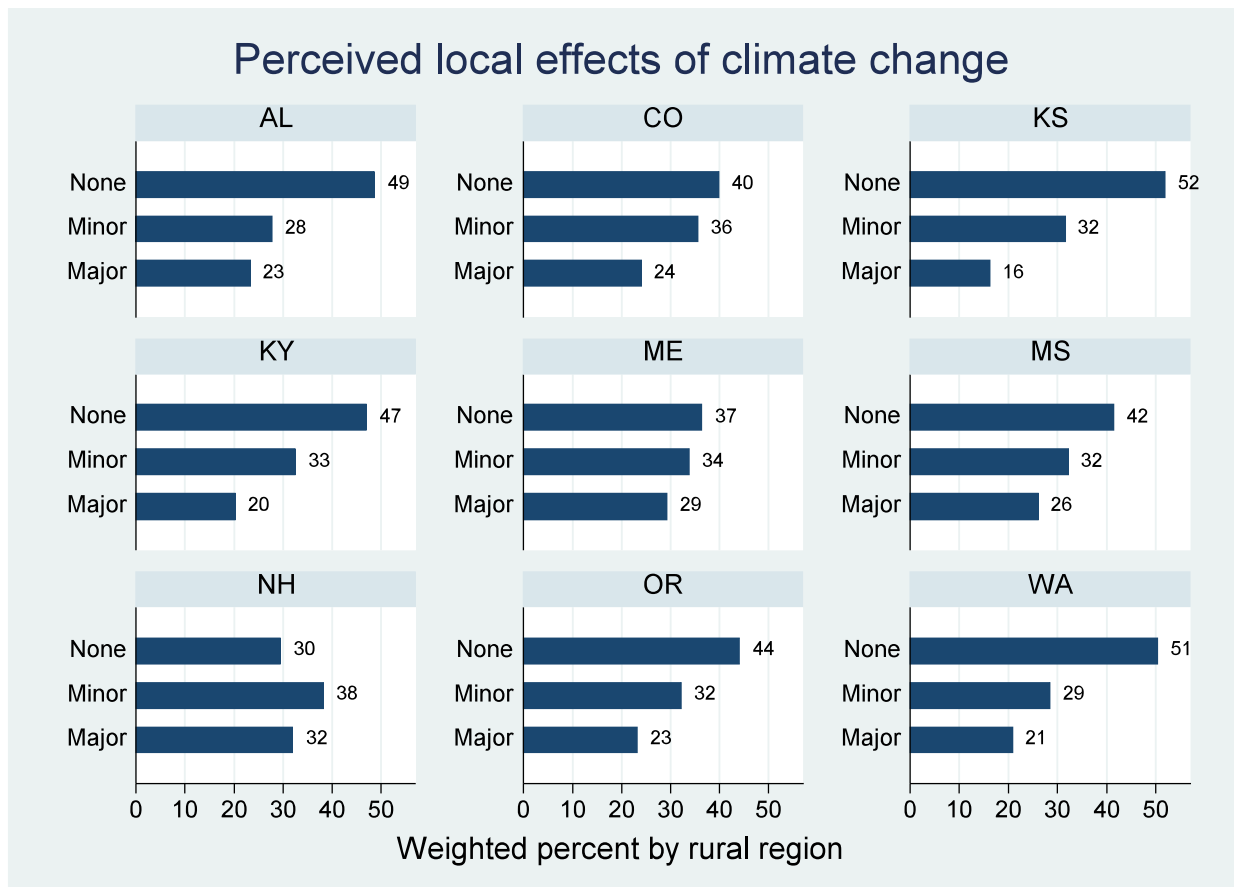

Figure 2: Perceived effects of climate change on respondent's community or family, by CERA region. 


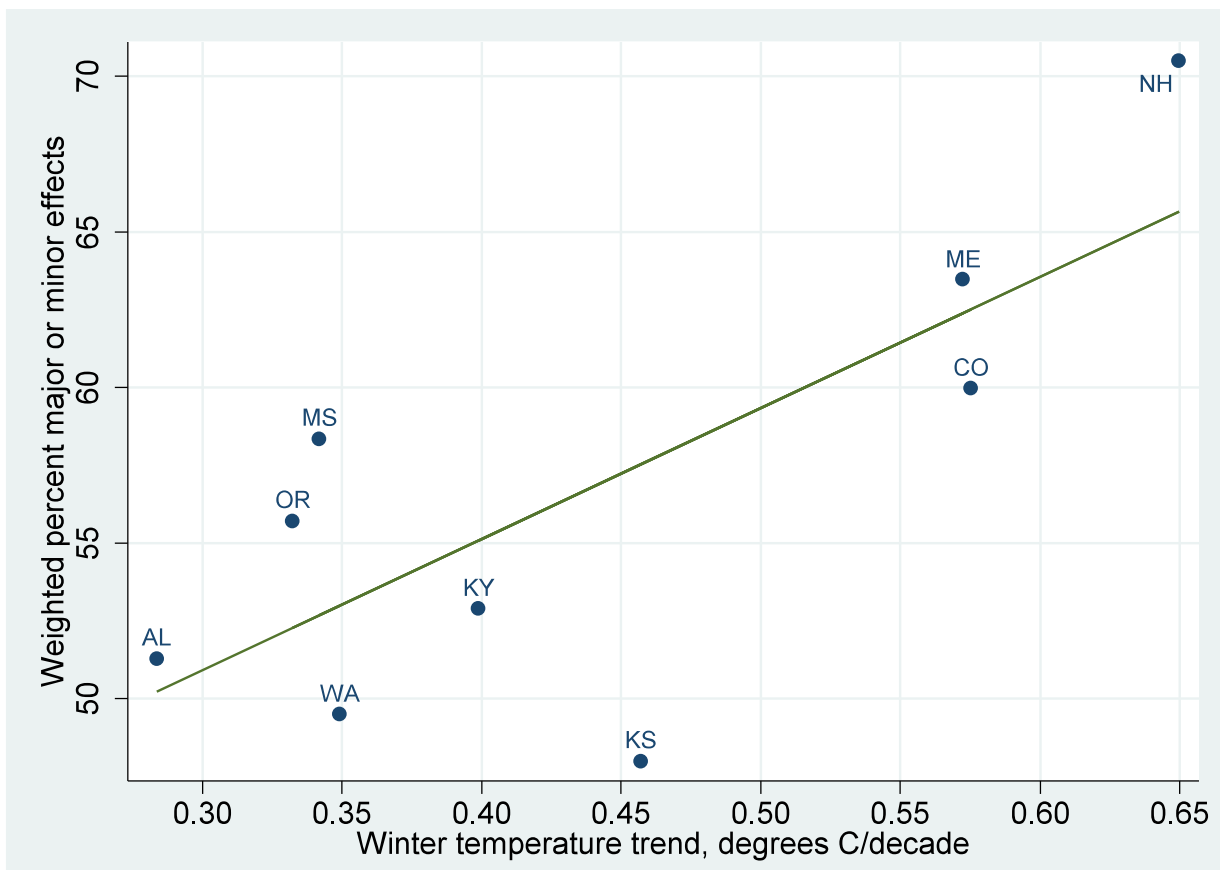

Figure 3: Weighted percent perceiving climate change effects vs. winter temperature trends by region. Robust regression line shown is resistant to outliers and does not assume normality $(p=.026$; see Hamilton 2009).

Table 1: Mixed-effects ordered logit regression of perceived local effects from climate change (Figure 2) on characteristics of individual respondents and winter temperature trends (Figure 3).

\begin{tabular}{llll} 
Predictors & coef. & SE & $\boldsymbol{p ~ ( z )}$ \\
\hline Individual-level fixed effects & & & \\
sex (0=male, 1=female) & .238 & .054 & .000 \\
race (0=white non-Hispanic, 1=other) & .062 & .089 & .483 \\
age (18 to 96 years) & -.003 & .002 & .067 \\
income class (1 to 6 scale for household quintiles \& top 5\%) & -.056 & .020 & .005 \\
education (1=8th grade or less, 7=postgraduate; centered) & -.017 & .017 & .313 \\
party (1=strong Democrat, 7=strong Republican; centered) & -.149 & .012 & .000 \\
$\quad$ education×party (interaction term) & -.024 & .007 & .001 \\
$\quad$ religious (0=never attend services, 4=twice or more/week) & -.060 & .020 & .002 \\
$\quad$ newcomer (0=lived here >5 years, 1=lived here $\leq 5$ years) & -.008 & .073 & .917 \\
cut1 & .280 & .232 & \\
cut2 & 1.770 & .234 & \\
\hline Region-level fixed effects & & & \\
$\quad$ winter temperature trend (degrees C/decade) & 1.923 & .409 & .000 \\
\hline Region-level random intercept & estimate & SE & $\boldsymbol{p}$ (LR) \\
\hline standard deviation & .127 & .105 & .008 \\
\hline
\end{tabular}

